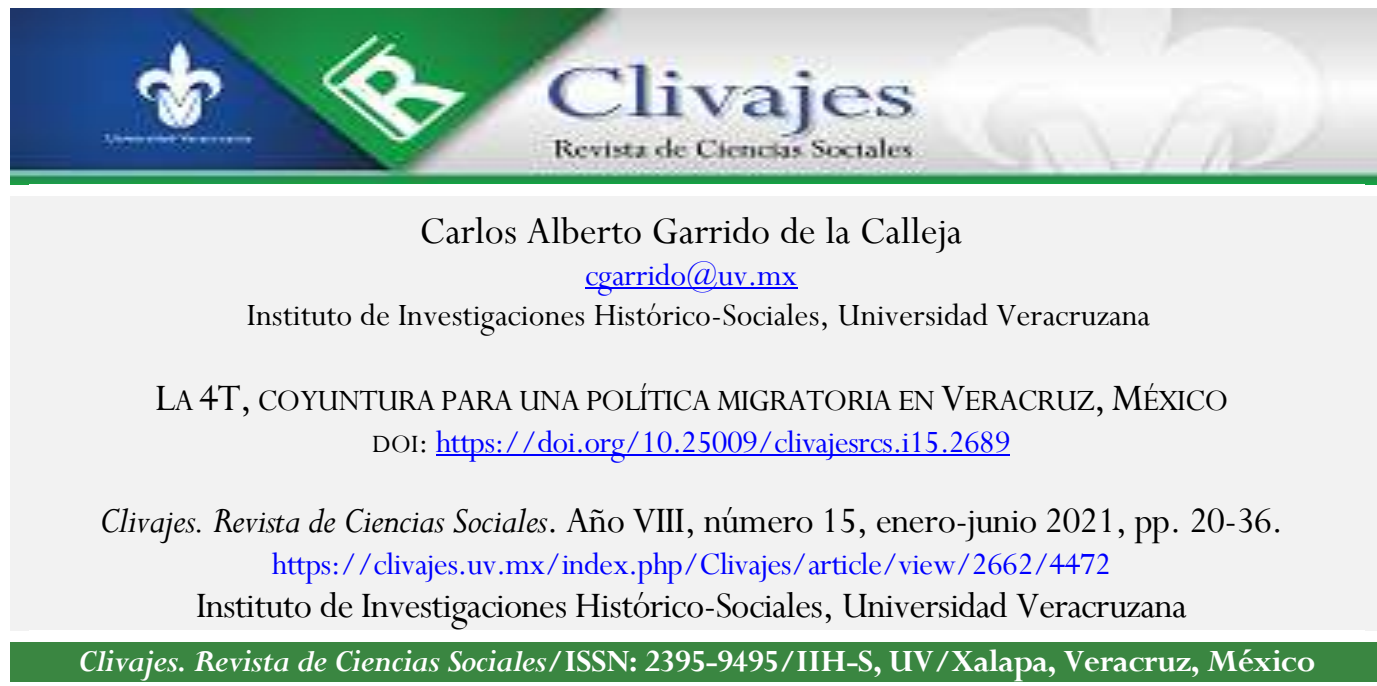

Recibido: 24/03/2021

Aceptado: $15 / 05 / 2021$

Dictaminado: 26/06/2021

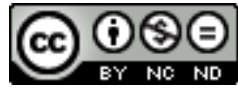

Clivajes. Revista de Ciencias Sociales (ISSN: 2395-9495), Año VIII, Núm. 15, enero-junio, 2021 Instituto de Investigaciones Histórico-Sociales, Universidad Veracruzana, México 


\title{
LA 4T, COYUNTURA PARA UNA POLÍTICA MIGRATORIA EN VERACRUZ, MÉXICO
}

\author{
Carlos Alberto Garrido de la Calleja*
}

\begin{abstract}
Resumen
El presente ensayo analiza el quehacer institucional que gobiernos estatales priistas y panistas establecieron para atender la realidad migratoria veracruzana. Resultado de este análisis, se sostiene que la actual administración morenista se encuentra ante un potencial escenario de cambio para ser la primera en promover, a través de la concurrencia de poderes, el diseño de una política migratoria integral e incluyente, con programas y protocolos específicos.

Palabras clave:

Política migratoria, Gobiernos estatales, Concurrencia de poderes, Agenda migratoria, Protocolos de atención
\end{abstract}

The 4T, JUNCTURE FOR A MigRATION POLICY IN THE STATE OF VERACRUZ, MEXICO

\section{Abstract}

This essay analyzes the institutional work that PRI (Institutional Revolutionary Party) and PAN (National Action Party) state governments established to address the reality of migration in Veracruz. As a result of this analysis, it is argued that the current administration of MORENA (National Regeneration Movement) is facing a potential scenario of change to be the first to promote, through the concurrence of powers, the design of a comprehensive and inclusive migration policy, with specific programs and protocols.

Keywords:

Migration policy, State governments, Concurrence of powers, Migration agenda, Attention protocols

\section{LA 4T, CONJONCTURE POUR UNE POLITIQUE MigRATOIRE À L’ÉtAT DE VERACRUZ, MEXIQUE}

\section{Résumé}

Ces derniers temps, l'action des gouvernements locaux dans les relations internationales a pris de l'importance ; cependant, on a peu abondé sur l'étude de la para-diplomatie à partir d'une perspective pratique et centrée dans un phénomène ou une réalité en particulier comme la migration. C'est pourquoi, dans cet essai on analyse l'élaboration de l'Annuaire de migration de Jalisco, de même que son importance pour les gouvernements et acteurs locaux intéressés à comprendre la migration à l'échelle locale et internationale.

Mots clés :

Politique migratoire, Gouvernements des États, Concurrence des pouvoirs, Agenda migratoire, Protocoles d'attention

* Profesor-investigador en el IIH-S de la UV, es miembro del Sistema Nacional de Investigadores y Perfil PROMEP. Actualmente dirige el Proyecto "Educación y migración de retorno. Propuestas de intervención”, es productor y conductor del programa "Veracruz, tierra de migrantes" de Radio uv, así como coordinador del suplemento periodístico del mismo nombre en La Jornada Veracruz; cuenta con diversas publicaciones sobre tema migratorio. 


\section{INTRODUCCIÓN}

El insumo teórico-práctico que nutre a este ensayo resulta del trabajo de campo realizado en los últimos diez años, analizando, para este caso, el quehacer gubernamental del estado de Veracruz. En este recorrido, se puso especial énfasis en indagar por qué, no obstante los discursos políticos prometedores de bienestar social, la realidad migratoria no fue incorporada como tema central en las agendas priistas y panistas. En este contexto, aquí se sostiene que la actual administración gubernamental $^{1}$ se encuentra ante un escenario promisorio e idóneo para diseñar una impostergable política migratoria estatal, fundada en la inclusión y el respeto a los derechos de poblaciones migrantes veracruzanas y no veracruzanas. En otras palabras, en este ensayo se argumenta que tal política migratoria es posible, articulando tanto la estructura como la coyuntura que en sí mismo representa como oportunidad de cambio el gobierno morenista, ante la otrora opacidad de administraciones priistas y panistas.

La estrategia no es sencilla, pero es posible. Exige un breve análisis situado (con perspectiva histórica-contextual) para identificar y atender los actuales dejos de administraciones pasadas, cuyos actores2 encubiertos continúan privilegiando intereses políticos y empresariales, tanto nacionales como internacionales, por encima del bienestar de las poblaciones migrantes. Resultado de lo anterior, la migración en Veracruz continúa rebasando la capacidad de respuesta institucional, donde el trabajo de la sociedad civil, de alguna forma, promueve y desarrolla acciones de intervención humanitaria, hasta cierto punto supletorias de las gubernamentales. Estas acciones representan un recordatorio social para que el gobierno estatal emprenda los cambios estructurales necesarios en sus instituciones y redirija su quehacer hacia las innovaciones jurídicas pertinentes a fin de responder a las necesidades, en constante cambio, y evitar que éstas rebasen nuestra capacidad de respuesta, como lo sigue haciendo actualmente la migración.

Concomitante a ello, el presente ensayo busca aportar argumentos que sirvan de insumo a las instituciones veracruzanas, en el diseño de una política migratoria capaz de articular la acción ejecutiva, legislativa y judicial. En este sentido, tales

\footnotetext{
${ }^{1}$ Desde el $1^{\circ}$ de diciembre de 2018, el estado de Veracruz es gobernado por el Ing. Cuitláhuac García Jiménez, militante del partido Movimiento Regeneración Nacional (MORENA).

${ }^{2}$ En el discurso, comulgan con las propuestas de cambio de la 4T, pero en la práctica operan con estrategias mediáticas y simuladoras (servidores públicos entrevistados durante el trabajo de campo en instituciones estatales de la ciudad de Xalapa, Veracruz, en el período 2015-2020).
}

Clivajes. Revista de Ciencias Sociales (ISSN: 2395-9495), Año VIII, Núm. 15, enero-junio, 2021 Instituto de Investigaciones Histórico-Sociales, Universidad Veracruzana, México 
argumentos crítico-propositivos se agrupan aquí en tres rubros; en el primero, se presenta una sucinta reconstrucción contextual del panorama migratorio veracruzano contemporáneo; en el segundo, se recogen de forma crítica aquellas políticas institucionales que desde su lógica los gobiernos previos (PRI-PAN) desplegaron para atender la realidad migratoria estatal; y, en el tercer rubro (Gobierno estatal y migración: un agenda social en proceso), se hace un balance crítico de los trabajos que hasta el momento la administración estatal morenista desarrolla para enfrentar esta realidad. En un esfuerzo de crítica propositiva, en el apartado de conclusiones, se plantean algunas propuestas que permitirían al gobierno estatal de la 4T, atender de forma integral la realidad migratoria veracruzana. ${ }^{3}$

\section{ACTUAL PANORAMA MIGRATORIO VERACRUZANO}

Si bien Veracruz constituye un importante polo de desarrollo económico para el país, ${ }^{4}$ paradójicamente se ubica entre los cinco estados con mayor índice migratorio, destacando, desde los años noventa, una crisis de salarios y empleos en sus campos agrícolas y zonas rurales, detonando permanentemente flujos migratorios hacia estados del norte y a los Estados Unidos. Estos flujos, cabe decir, generan a su vez una ausencia de mano de obra local que se cubre con la contratación de trabajadores inmigrantes regionales temporales (en su mayoría, de comunidades de otros estados) e internacionales; estos últimos generalmente provenientes de Centroamérica y recientemente de África (Garrido y Zavaleta, 2020).

Esta realidad propicia que en Veracruz converjan diversos flujos y tipologías migratorias, dando como resultado circuitos migratorios, que hoy en día nos permiten hablar de una migración consolidada y, hasta ahora, desapercibida por las políticas públicas locales. Por ello, se puede afirmar que Veracruz, alberga un proceso migratorio social complejo, que, basado en una migración internacional acelerada, se consolida entre los años 1985 y 2005. Durante este periodo, los migrantes veracruzanos tienen mayor presencia en las etapas de salida, cruce fronterizo y llegada. ${ }^{5}$ Es importante destacar que sus flujos migratorios se han dirigido tanto a

\footnotetext{
${ }^{3}$ Cabe señalar que estas propuestas se enriquecen del hacer, pensar y sentir de personas migrantes entrevistadas en los últimos cinco años.

${ }^{4}$ Se ubica entre las diez entidades generadoras del 60\% del Producto Interno Bruto, al cual, aporta el 5\%, (INEGI, 2020).

${ }^{5}$ Estas son tres de las siete etapas del proceso migratorio veracruzano: premigratoria, migratoria/operativa, transitoria, fronteriza, de llegada/arribo al destino (estado fronterizo o estadunidense), de retorno (ya sea voluntario, involuntario, deportación) y de re-emigración.
}

Clivajes. Revista de Ciencias Sociales (ISSN: 2395-9495), Año VIII, Núm. 15, enero-junio, 2021 Instituto de Investigaciones Histórico-Sociales, Universidad Veracruzana, México 
ciudades fronterizas del norte del país, como a los Estados Unidos (apoyados en circuitos migratorios ya existentes).

De acuerdo con lo anterior, se observa que, como resultado de la dinámica migratoria que subyace a las mencionadas etapas, a la fecha, por un lado, se han mantenido flujos de migrantes veracruzanos hacia estados del norte del país. Por lo que se estima que entre las ciudades fronterizas industriales de Tijuana (Baja California), Ciudad Juárez (Chihuahua), Reynosa y Matamoros (Tamaulipas), así como en zonas agrícolas de los estados de Sinaloa y Sonora, existe una población de 600000 veracruzanos, a la que se suman los casi 900000 veracruzanos distribuidos en ciudades y condados de los Estados Unidos (INEGI, 2020). Por otro lado, se han incrementado los desplazamientos y migraciones forzadas, resultado del alza delictiva, que se traducen en asaltos, secuestros, violaciones, desapariciones, amenazas. Al respecto, lo que resulta criticable es el desconocimiento y la falta de atención institucional a las problemáticas que acompañan a esta nueva tipología migratoria.

En suma, este es el contexto migratorio que hereda el actual gobierno estatal, resultado de las acciones estructurales priistas y panistas, que, sin embargo, representan una coyuntura para desincoporarlas del quehacer institucional. Para contribuir a ello, en los siguientes rubros se expone un breve análisis del sesgado quehacer que esas administraciones promovieron para omitir el diseño de la política migratoria sugerida en este ensayo.

\section{POLÍTICAS PRIISTAS Y PANISTAS EN LA MIGRACIÓN VERACRUZANA}

No obstante el interés social argumentado por la administración del entonces gobernador Miguel Alemán Velasco, en el periodo de 1998 a 2004, la incorporación de la realidad migratoria a la agenda estatal no respondió directamente a la muerte de veracruzanos en el desierto de Yuma (Arizona), ocurrida en mayo de 2001, mucho menos al compromiso de apoyar a sus familiares. Por lo contrario, respondió a los intereses políticos y financieros que, aunado a las remesas veracruzanas, representaba crear una Oficina de Atención a Migrantes. ${ }^{6}$

Cabe destacar que esta lamentable coyuntura, lejos de asumirse como una oportunidad para transformar dicha Oficina de Atención a Migrantes en un Instituto de Asuntos Migratorios con capacidad presupuestal y facultades jurídicas para proponer

${ }^{6}$ Ex servidor público del gobierno del estado de Veracruz, quien pidió no ser identificado (Segunda entrevista realizada en julio de 2020, en Xalapa, Veracruz).

Clivajes. Revista de Ciencias Sociales (ISSN: 2395-9495), Año VIII, Núm. 15, enero-junio, 2021 Instituto de Investigaciones Histórico-Sociales, Universidad Veracruzana, México 
acciones legislativas migratorias, ${ }^{7}$ se apoyó en viejas prácticas partidistas clientelares: se dedicó a promoverse como benefactora de los migrantes, entregando láminas de cartón, despensas y costales de semillas (frijol, maíz, arroz y lentejas) tanto a comunidades veracruzanas expulsoras, como a los albergues encargados de ofrecer alimentos a los migrantes de paso.

\section{USO POLÍTICO DE LOS MIGRANTES Y CONTINUIDAD DEL PRI EN EL GOBIERNO ESTATAL}

En el marco del proceso electoral del año $2010,{ }^{8}$ nuevamente la migración de veracruzanos jugó un papel fundamental en el terreno político. Bajo el argumento de ofrecerles trabajo formal (de base) en Veracruz, más de 3500 veracruzanos (llamados “juarochos") aceptaron la propuesta de ser "rescatados" de la violencia urbana en Ciudad Juárez (Chihuahua) y de las injusticias laborales vividas en las maquiladoras (Barrios, 2016; Garrido, 2017).

A las y los migrantes se les prometió empleos, servicios de salud, acceso a escuelas, traspaso o tramitación de nuevos créditos hipotecarios con el Instituto del Fondo Nacional de la Vivienda para los Trabajadores (INFONAVIT), entre otros apoyos que nunca recibieron. En lo mediático, esta estrategia política ofreció al gobierno estatal priista una percepción de sentido social, pero en la realidad los "juarochos", además de los problemas de reinserción social que vivían, nunca recibieron los apoyos institucionales prometidos. Por ejemplo, en la educación, con el argumento de "no contar con papeles originales", escuelas de diferentes niveles (universidades, preparatorias, secundarias, primarias y jardines de niños) obstaculizaron la inscripción o reinscripción de niños y jóvenes juarochos.

El sector salud no fue la excepción. Algunos "juarochos" fueron notificados vía telefónica de que, por ser veracruzanos en "situación especial”, tenían acceso al entonces Seguro Popular en el momento que lo requirieran; se les exhortaba a solicitarlo en las instancias pertinentes. Sin embargo, cuando buscaron este beneficio, contradictoriamente se les exigía documentación oficial que comprobara su identidad veracruzana, cuando la mayoría de ellos había regresado sin documentación oficial, o bien con documentación que acreditaba domicilios en el estado de Chihuahua. Por esta razón no recibieron el servicio en los Centros de Salud veracruzanos.

\footnotetext{
${ }^{7}$ Esto habría permitido trabajar concurrentemente con la federación para diseñar una ley y una política migratoria regionales, como en su momento lo hicieron las Oficinas de Atención a Migrantes en los estados de Michoacán y Zacatecas.

${ }^{8}$ Promovido por el entonces gobernador priista Fidel Herrera Beltrán (2004-2010). 
La situación más delicada fue y sigue siendo la del empleo prometido. Las palabras de algunos “juarochos” entrevistados expresan más que cualquier otro análisis:

Por eso nos animamos a venirnos, nos dijeron que acá nos iban a apoyar con trabajos y créditos para casas y no lo pensamos dos veces... y más si nos dijeron que nos fuéramos sin nada [de regreso a Veracruz], allá dejamos todo en Ciudad Juárez (Doña Ofelia, Boca del Río, Veracruz)

Mira, cuando llegamos y nos recibieron con música y hasta el gobernador estaba ahí, la verdad yo sí me sentí en casa. Sentí que ya la habíamos hecho aunque regresamos sin nada, sentí que aquí la podríamos hacer. El mismo alcalde de Xalapa me dio su tarjeta y me dijo "búscame a la hora que quieras para hablar y apoyarte con lo que necesites, lo que quieras". Y como sabíamos que también era empresario, pues nos dio muchas esperanzas" (Don Luis, Xalapa, Veracruz).

Ante la falta del apoyo anunciado, varias familias "juarochas" regresaron a Ciudad Juárez, pero sólo a vender, rematar (malbaratar) o devolver el crédito hipotecario (INFONAVIT), ya que en la Delegación de Veracruz no recibieron apoyo para realizar el traspaso prometido.

A la fecha, varios "juarochos" han retornado a Ciudad Juárez, y los que permanecen en la entidad veracruzana viven con familiares, amigos, rentan o, incluso, como estrategia de subsistencia, han repartido a los miembros de sus familias (hijos, sobrinos, abuelos) entre la familia extensa. Otros, cuyos ahorros o trabajos informales se los permiten (de forma limitada), rentan habitaciones de una sola pieza, preferentemente en vecindades (cuarterías) donde la cercanía con vecinos permite convivir y pedir algún tipo de favor: café, "un taco", bañarse con agua caliente.

El pago de estos favores se hace con trabajo doméstico: trapear, barrer, apoyar en la preparación de alimentos, cuidar niños, hacer mandados, lavar platos o ropa. Los $\$ 10$ o $\$ 15$ pesos de cuota fija en los comedores populares resultaron y siguen resultando atractivos para aquellos "juarochos" que no quieren "dar más lata a los familiares", “cambiarle un poquito a lo que siempre cocinas" ,o para quienes quieren cocinar en casa (cuarto rentado), donde generalmente no tienen aparatos electrodomésticos o de línea blanca para calentar y conservar los alimentos: "lo que ves es todo lo que tenemos (...) si no nos comemos todo en el día, se nos echa a perder la comida” (Doña Luz, Xalapa, Veracruz).

Para estas personas, "llevarse bien" con los vecinos es la puerta para ser recibidos e incluso invitados a comer en el algún momento del día: "tienes que granjearte con los 
demás para estar bien” (Don Luis, Xalapa, Veracruz). Aprovechando la temporada otoñal e invernal, algunos de los "juarochos" rifan sus chamarras, abrigos, sweaters, bufandas, gorros; otros, hacen venta de garaje (o en cualquier espacio del lugar donde vivan). A fin de cuentas, en sus palabras: "en Xalapa hace frío, pero no hay ropa de ésta que es para las nevadas de Juárez, y que es muy calientita y buena”.

Con la simulación de esta repatriación" a través del Programa "Veracruz sin Fronteras", 10 el gobierno priista en turno, mediática y electoralmente ganaba terreno en las elecciones en puerta, lo cual no fue definitivo, pero se reflejó en la continuidad del partido-gobierno en la gubernatura veracruzana.

\section{USOS PRIISTAS DE LOS TEMAS MIGRATORIOS}

El Programa Veracruz sin Fronteras duró sólo los cuatro meses previos a las elecciones estatales de 2010. Pudo haber sentado un precedente para diseñar una política migratoria, pero careció de una estructura que permitiera evaluar, diagnosticar y sistematizar el impacto de sus acciones.

Iniciada la nueva administración estatal priista ${ }^{11}$ (continuación de la anterior), se generaron expectativas respecto a la posibilidad de contar con una política migratoria. Se tenía el antecedente del Programa "Veracruz sin Fronteras" y, paralelo a ello, se habían celebrado diversos talleres regionales, recogiendo información sobre las problemáticas más apremiantes. La migración fue una de ellas y, teniendo como insumos los resultados de un diagnóstico social realizado en 2008 por la Universidad Veracruzana (Garrido, 2017), el Plan Veracruzano de Desarrollo “duartista” incorporó la migración como una realidad social conformada por etapas ${ }^{12}$ sobre las cuales era imperativo elaborar diagnósticos específicos para que, en función de ellos, se diseñaran tanto una política migratoria como proyectos, protocolos y acciones que permitieran atender a poblaciones migrantes veracruzanas y no veracruzanas (PDV, 2011; Garrido, 2017).

${ }^{9}$ No obstante la connotación política del programa, guardaba un sesgo conceptual al llamar repatriación al traslado aéreo y terrestre de veracruzanos que seguían viviendo en su país, en su propia patria y no en el extranjero, donde tendría mayor pertinencia el concepto.

${ }^{10}$ Desde el año 2010, se solicitó, sin conseguirlo, acceso al documento de este Programa. El argumento (recibido verbalmente) en 2012 fue: "es confidencial”; en 2015: “ya no existe, ya pasó ese programa”; y, en febrero de 2017 (bajo la administración panista), la respuesta fue: "no hay copia de ese programa en los archivos que recibimos". Este último argumento pudo tener sentido por ser nueva administración (Entrevista informal al director de Atención a Migrantes).

${ }^{11}$ Encabezada por el gobernador en turno Javier Duarte de Ochoa (2010-2016)

12 Premigratoria, migratoria/operativa, transitoria, fronteriza, de llegada/arribo al destino (estado fronterizo o estadunidense), de retorno (ya sea voluntario, involuntario, deportación) y de reemigración.

Clivajes. Revista de Ciencias Sociales (ISSN: 2395-9495), Año VIII, Núm. 15, enero-junio, 2021 Instituto de Investigaciones Histórico-Sociales, Universidad Veracruzana, México 
Sin embargo, una vez iniciado su periodo de gobierno, el ejecutivo estatal, a través de la Oficina de Atención a Migrantes y el Congreso Local del Estado, evadieron las propuestas que hicieron académicos y sociedad civil para traducir en una política migratoria lo escrito en el Plan Veracruzano de Desarrollo. ${ }^{13}$ El argumento oficial fue: "El estado de Veracruz no puede legislar en materia migratoria, es un tema de competencia federal”. ${ }^{14}$

Pese a lo anterior, de forma mediática, electoral y contradictoria, las acciones asistencialistas continuaron. El objetivo político seguía siendo mostrar un gobierno preocupado por la migración, pero la centroamericana, no la veracruzana (para ello y bajo esta nueva administración estatal, la Oficina pasó a ser Dirección General de Atención a Migrantes). Prueba de ello fue el apoyo ofrecido a las "Patronas". ${ }^{15}$ En 2012, el ejecutivo estatal les prometió infraestructura necesaria para rehabilitar su comedor comunitario $y$, sobre todo, para construir una rampa de concreto desde donde lanzaran los alimentos a las y los migrantes, disminuyendo así su exposición a sufrir accidentes junto a las vías del tren. El apoyo aún sigue en proceso: “¿Recibieron ese apoyo, Norma?" [Esboza una sonrisa, mientras mira hacia el horizonte.] "No, todavía no", responde. ${ }^{16}$

El Congreso Local, ${ }^{17}$ por su lado, lejos de asistir a comunidades rurales, indígenas, albergues o comedores para migrantes centroamericanos, se dedicó exclusivamente a promover eventos internacionales y participar en ellos ${ }^{18}$ (con sus homólogos de otros congresos legislativos) ${ }^{19}$, discutiendo y manifestando su preocupación por la seguridad laboral de las y los migrantes mexicanos en los Estados Unidos. Es importante destacar que, no obstante los esfuerzos centrados en este trabajo internacional (de turismo político), no se establecieron vínculos de trabajo, por ejemplo, con la Casa Veracruz en Los Ángeles, ${ }^{20}$ la Federación de Veracruzanos en

${ }^{13}$ Propuesta por investigadores de la Universidad Veracruzana.

${ }^{14}$ Entrevista con legisladores integrantes de la Comisión Permanente del Congreso Local (Legislatura XVII) y personal de la Dirección de Asuntos Jurídicos del Gobierno del Estado de Veracruz. Agosto-noviembre, 2011 y 2014.

${ }^{15}$ Grupo de mujeres voluntarias, nativas de la comunidad de Guadalupe (La Patrona), en el municipio de Amatlán de los Reyes, Veracruz. De acuerdo con Norma Romero, su líder, iniciaron esta ayuda humanitaria en el año de 1995; consiste en ofrecer alimentos, principalmente "empaquetados" en bolsas de plástico y lanzados a migrantes que viajan en el tren conocido como "La Bestia”. Este trabajo humanitario las llevó a recibir el Premio Nacional de Derechos Humanos (2013), ser nominadas en el año 2015 al Premio Princesa de Asturias de la Concordia y recibir la medalla al Mérito por la Universidad Veracruzana en 2016.

16 Entrevista con Norma Romero (líder de las Patronas), durante la entrega de la Medalla al Mérito (Universidad Veracruzana). Xalapa, Veracruz; mayo, 2016.

${ }^{17}$ Integrantes de la Comisión de Derechos Humanos y Atención a Grupos Vulnerables y Migrantes. Legislatura LXIII.

${ }_{18}$ Teniendo como principales lugares para celebrar estas reuniones, las ciudades norteamericanas de Los Ángeles, Houston, Chicago y Nueva York.

${ }^{19}$ Integrantes también de la Coordinación Nacional de Diputados y Líderes Migrantes (CONADYM).

${ }^{20}$ Esta Casa fue financiada por el Senador Héctor Yunes Landa, otrora candidato a la gubernatura del estado de Veracruz (2016). 
Santa Ana (ambas organizaciones en el estado de California) o la Asociación de Mexicanos en Carolina del Norte (AMEXCAN).

Por enésima vez, lo que pudo haber sido una oportunidad para proponer el diseño de una ley y política migratoria, se diluyó en el trabajo mediático de esta Comisión Legislativa de Derechos Humanos y Atención a Grupos Vulnerables y Migrantes, del Congreso Local del estado de Veracruz.

Sin embargo, con una labor poco difundida ${ }^{21}$ pero asertiva, y contrariamente a la lógica asistencialista del ejecutivo y legislativo veracruzanos, la Fiscalía de Atención a Migrantes mostró un quehacer proactivo, pero limitado por el mismo ejecutivo. Durante el periodo 2011-2013, atendió en promedio 300 denuncias anuales. Poco más del 20\% de esas denuncias fueron procesadas y otras más se dejaron en curso, bajo el supuesto de que serían retomadas por la siguiente administración estatal (panista), la cual sólo duró dos años debido a la reforma política que homologó las elecciones locales para gobernador y diputados, de modo que los últimos pudieran reelegirse hasta por cuatro períodos. ${ }^{22}$ En esta contienda, resultó electo Miguel Ángel Yunes Linares, candidato del Partido Acción Nacional (PAN), quien ya con la envestidura de gobernador, como se analiza en el siguiente rubro, desestimó también la realidad migratoria como punto prioritario de su agenda estatal.

\section{LA MIGRACIÓN VERACRUZANA EN EL GOBIERNO ESTATAL PANISTA}

En Veracruz, la administración estatal panista tuvo un margen temporal bastante breve, ${ }^{23}$ situación que fue tomada como excusa para no bosquejar al menos un proyecto de ley migratoria regional, así como una urgente estrategia operativa de atención integral a migrantes veracruzanos y no veracruzanos. En este sentido, las acciones migratorias estatales, al igual que en la administración priista, siguieron ejecutándose desde la Dirección General de Atención a Migrantes. A través de esta dependencia, más que promover por lo menos acciones complementarias y coordinadas con la federación ${ }^{24}$ para atender necesidades humanas demandadas por estas poblaciones

\footnotetext{
21 Debido, quizás, al impacto político que implicaba dar a conocer las violaciones que sufrían los migrantes centroamericanos a su paso por territorio veracruzano.

${ }^{22}$ Reforma Político-electoral aprobada en el año 2014, en sesión del pleno, por la LXIII Legislatura local de Veracruz. Tal reforma a la Constitución Política del estado de Veracruz estipuló que, para 2016 y por única ocasión, habría un gobierno de dos años y también diputados (bianuales).

${ }^{23}$ Periodo del $1^{\circ}$ de diciembre del 2016 al $1^{\circ}$ de diciembre del 2018.

${ }^{24}$ Estas acciones deben realizarse en coordinación con la delegación de la Secretaría de Relaciones Exteriores (SRE), así como con los consulados, programas federales de protección a migrantes y con el Instituto Nacional de Migración. 
migrantes, el gobierno estatal en turno centró su actuación en acciones paliativas y superficiales, como las siguientes:

- Ofrecer documentación (actas del registro civil, constancias y certificados) requeridos por los migrantes o sus familiares.

- Aportar recursos para el traslado de restos y enfermos, así como información sobre detenidos en cárceles de los Estados Unidos y asistencia a familiares para la búsqueda de personas desaparecidas en territorio estadounidense.

- Emprender acciones mediáticas, entre las que destaca la entrega de despensas a ciertos albergues que ofrecían apoyo a migrantes centroamericanos.

El más claro margen de maniobra política y económica del gobierno panista fue, sin duda alguna, el Fondo de Apoyo a Migrantes (programa eliminado por el actual gobierno federal), el cual, constituyó la mayor partida presupuestal para la Dirección General de Atención a Migrantes (más de 40 millones de pesos recibidos en los dos años que duró esta administración).

Es menester señalar que, no obstante haber recibido esta partida federal, la implementación de tal Fondo reprodujo la misma forma operativa del PRI. Esto era de esperarse, ya que los recién llegados y proclamados políticos del cambio, independientemente de resultar de la alternancia partidista hacia el PAN (alianzas pragmáticas con el PRD y otros partidos), ingresaron y crecieron en la política dentro de las filas del PRI. Esto implicó que sus prácticas políticas se asociaran y alinearan con el priismo del entonces presidente Enrique Peña Nieto, cuyo gobierno siguió careciendo de una política migratoria nacional.

A la luz de lo anterior, el gobierno veracruzano siguió promoviendo una acción migratoria (no así una política migratoria regional), reproductora del centralismo federal. Se dedicó a gestionar los programas e iniciativas de forma jerárquica, reactiva, paliativa y mediática, sobreponiendo intereses políticos y financieros a las necesidades de las poblaciones migrantes.

En otras palabras, bajo el gobierno panista hubo respuestas institucionales en materia migratoria, principalmente de forma reactiva y atomizada, que carecían de una visión de largo plazo y omitían considerar los procesos migratorios de forma integral, es decir, desde su origen o sus causas; con ello se contribuyó clara e intencionalmente a reproducir la hegemonía centralista migratoria del gobierno federal priista (Ortega y Garrido de la Calleja, 2019). 
Al igual que durante el priismo, se careció de un trabajo pertinente, incluyente y visionario en asuntos migratorios. No se asumió la necesidad de una política migratoria con dimensión proactiva, cuyas medidas legislativas, operativas y presupuestales, permitieran garantizar derechos y servicios tanto a migrantes como a personas extranjeras. Más bien se siguió la lógica asistencialista con fines clientelares.

Lamentablemente se mantuvo el centralismo y el autoritarismo del poder ejecutivo estatal, a lo cual se sumó la reproducción ideológica, acrítica y servilista de los poderes legislativo y judicial (limitando su quehacer sobre el tema a las indicaciones del ejecutivo), por lo que prevaleció el interés en lo político y financiero. Estas acciones también se acompañaron de una manipulación mediática (de acciones asistencialistas en materia migratoria) y una simulación en la inversión de recursos ${ }^{25}$ para las comunidades migrantes (Garrido de la Calleja y Zavaleta Betancourt, 2020).

La dependencia intencionada que, bajo el panismo, el ejecutivo veracruzano mantuvo respecto a las indicaciones de la Federación no sólo generó un distanciamiento entre sus políticas y sus migraciones, sino que se tradujo en opacidad e irresponsabilidad social, al no diseñar políticas públicas específicas, lo cual reflejó un desinterés humano, social, institucional, gubernamental por las personas migrantes. No obstante, en 2018 se asoma la posibilidad de resarcir la deuda histórica planteada, con la llegada de un gobierno morenista, electo para lograr los cambios que no quisieron hacer las administraciones estatales arriba mencionadas.

\section{GOBIERNO ESTATAL Y MIGRACIÓN: UN AGENDA SOCIAL EN PROCESO}

Con la llegada del Movimiento de Regeneración Nacional (morena) al gobierno federal, crece la expectativa con respecto a posibles beneficios para las personas migrantes; por ejemplo, se espera que se diseñe una política migratoria integral fundamentada en la inclusión y el respeto a los derechos de poblaciones migrantes tanto mexicanas como no mexicanas. En otras palabras, se espera y se busca que el gobierno de la 4T aborde a la migración como una compleja realidad estructural y no como un tema administrativo coyuntural, tal como fue abordado por los gobiernos predecesores (Ortega y Garrido de la Calleja, 2019; Fitzgerald, 2014).

No obstante estas expectativas, se debe tener claro que todo cambio requiere de un proceso gradual, participativo, y el estado de Veracruz no está exento de ello. En

${ }^{25} \mathrm{Al}$ final de la administración panista, no se comprobó el ejercicio de 17 millones de pesos del programa 3x1 de coinversión de remesas, destinado a fortalecer la infraestructura de municipios veracruzanos (Ortega y Garrido de la Calleja, 2019).

Clivajes. Revista de Ciencias Sociales (ISSN: 2395-9495), Año VIII, Núm. 15, enero-junio, 2021 Instituto de Investigaciones Histórico-Sociales, Universidad Veracruzana, México 
este contexto, tanto la academia como la sociedad civil están obligadas a sumarse al cambio (exigido y a la vez obstaculizado por administraciones priistas y panistas), desde una postura crítica-propositiva capaz de generar información para que el actual ejecutivo estatal observe que:

- Se sigue careciendo de una estrategia clara de atención integral a las problemáticas y necesidades de migrantes veracruzanos y no veracruzanos.

- No obstante contar con personal con experiencia nacional e internacional en asuntos migratorios, la Dirección General de Atención a Migrantes continúa promoviendo actividades superficiales, administrativas, paliativas y mediáticas. Algunas de estas actividades son, por ejemplo, informar sobre cómo obtener duplicados de actas de nacimiento, de matrimonio; distribuir folletos de instituciones y organismos nacionales e internacionales. ${ }^{26} \mathrm{Si}$ bien es cierto que estas actividades orientan parcialmente la realización de trámites, no constituyen acciones estructurales que resulten de una política migratoria integral.

- Prevalece un protagonismo institucional y una innecesaria duplicidad de funciones. ${ }^{27}$ Muestra de esto es la recién creada Dirección General de Cultura de Paz y Derechos Humanos, ${ }^{28}$ la cual ha venido no sólo a duplicar, sino a limitar hasta cierto punto las ya incipientes funciones de la Dirección General de Atención a Migrantes (DGAM) y los trabajos de la Comisión Estatal de Derechos Humanos (CEDH) en lo que se refiere a asuntos migratorios. Cabe señalar que paradójicamente, desde su creación a la fecha, por un lado, se han incrementado las violaciones a los derechos humanos y desapariciones de migrantes de paso, o bien durante su breve estancia por territorio veracruzano (generalmente migrantes centroamericanos, africanos y asiáticos). Aunado a lo anterior, esta Dirección ha desplazado de facto algunas acciones centrales que le corresponden a la Dirección General de Atención a Migrantes como, por ejemplo, las reuniones con el Instituto Nacional de Migración, con los consulados de Centroamérica, con organismos

${ }^{26}$ Información de la Secretaría de Relaciones Exteriores para el trámite de pasaportes, de la Embajada de los Estados Unidos para el trámite visas, de la Comisión Nacional de Derechos Humanos, e información de algunas dependencias estatales, por mencionar algunos ejemplos.

${ }^{27}$ Lo que impide un trabajo interinstitucional, intersectorial e interdisciplinario y por consiguiente, el diseño de una política migratoria estatal.

${ }^{28}$ En este contexto, y contrario a la encomienda de promover la paz y justicia en la entidad veracruzana, pese al incremento de la inseguridad y violencia exacerbada, esta Dirección hasta el día de hoy, no se ha pronunciado para que el gobierno de la 4T, reconozca a la creciente migración forzada (traducida en familias desplazadas) como consecuencia humanitaria.

Clivajes. Revista de Ciencias Sociales (ISSN: 2395-9495), Año VIII, Núm. 15, enero-junio, 2021 Instituto de Investigaciones Histórico-Sociales, Universidad Veracruzana, México 
internacionales, y la organización de trabajos interinstitucionales en asuntos migratorios.

- Se carece de un trabajo concurrente. Sin duda alguna, esta duplicidad de funciones, desgaste e innecesario protagonismo institucional, resta al gobierno veracruzano capacidad para convocar al trabajo corresponsable y concurrente con los tres poderes de gobierno. Trabajo al que se sumarían la sociedad civil y la academia para continuar diseñando (y ejecutando) acciones que permitan legislar, recomendar, crear puntos de acuerdo, dictámenes o resoluciones en asuntos migratorios. La ausencia de este trabajo concurrente e incluyente, posiciona a Veracruz (en el plano nacional e internacional) como una entidad federativa para la cual la migración no es prioritaria en su agenda gubernamental. Esto se refleja en la ausencia de una Comisión Especial en Asuntos Migratorios en su Congreso Local, la ausencia de una política migratoria integral y, en consecuencia, de protocolos específicos de atención a poblaciones migrantes veracruzanas y no veracruzanas.

Desde nuestra modesta consideración, el gobierno veracruzano, aún cuenta con el tiempo suficiente para cumplir las expectativas del cambio social promovido en campañas electorales. Construir una agenda migratoria integral, que atienda la realidad que viven los migrantes en cada etapa y tipología migratoria, permitirá no sólo romper con el lastre histórico heredado por gobiernos priistas y panista, sino responder a la realidad contemporánea de su población y territorio.

\section{CONCLUSIONES}

Los argumentos vertidos en este ensayo permiten sostener que no obstante el crítico escenario migratorio aquí analizado, el actual gobierno veracruzano aún tiene la posibilidad de resarcirlo y pasar de actividades mediáticas y reacciones paliativas a respuestas estructurales surgidas de una política migratoria estatal. La Constitución Política de los Estados Unidos Mexicanos se lo permite, ya que faculta a las entidades para legislar en torno a determinadas necesidades sociales que afectan a su territorio y población (Bobes y Pardo, 2016). En otras palabras, este precepto constitucional permite al gobierno estatal buscar en los poderes de concurrencia el fundamento legal para legislar en beneficio de poblaciones migrantes veracruzanas y no veracruzanas. Argumento legislativo al cual podemos sumar lo contenido al respecto en la 
Constitución de la entidad veracruzana; ésta señala que autoridades e instituciones estatales promoverán las condiciones necesarias para el pleno goce de la libertad, igualdad, seguridad y la no discriminación de las personas en territorio veracruzano, (Garrido de la Calleja, 2017).

Sin duda alguna, estos preceptos constitucionales ofrecen al gobierno de Veracruz la facultad para diseñar una agenda legislativa en materia migratoria, la cual, entre otros puntos, podría promover un trabajo concurrente ${ }^{29}$ entre la federación, el gobierno veracruzano y los municipios. Este trabajo permitirá romper con la mirada política de arriba hacia abajo, centralista y sesgada (Filomeno, 2017; Gulasekaram y Karthick, 2015), reconociendo así las características, complejidades y demandas migratorias propias de la entidad veracruzana (Pérez, 2007; Garrido de la Calleja, 2017).

Lograr lo anterior ofrecerá las condiciones legislativas necesarias para diseñar una política migratoria concurrente, basada en el respeto, la inclusión y la tolerancia a la diversidad de poblaciones migrantes veracruzanas y no veracruzanas. Tal política deberá acompañarse de protocolos específicos que atiendan, por ejemplo, necesidades educativas, de salud y trabajo, entre otras urgentes (Imaz, 2011; Araya y Xavier, 2008).

En suma, el gobierno de Veracruz necesita construir una nueva narrativa migratoria que promueva la concurrencia y armonía de las leyes federales, estatales y municipales, auspiciando así el diseño de una política migratoria que no se limite a ofrecer reacciones institucionales mediáticas, sino que aborde la realidad migratoria con una estrategia integral que incorpore el hacer, pensar y sentir de los migrantes, la academia, las instituciones y grupos sociales, religiosos y filantrópicos.

\section{REFERENCIAS}

ARAYA, M. Y GODAS, X. (2008). Migraciones: un nuevo ámbito de cooperación entre gobiernos locales, Montevideo. Observatorio de Cooperación Descentralizada Unión Europea-América Latina. Recuperado de https://bit.ly/3yYoTCr.

${ }^{29}$ Estos trabajos legislativos concurrentes deben ser incluyentes, sin distinguir origen, opinión política raza, color, sexo, idioma, religión, actividad o condición social. 
Barrios DE LA O, M. I. (2016). Movilidad humana en Ciudad Juárez 2017-2012. Transitando de la inmigración laboral a la emigración y desplazamiento forzado. El Colegio de la Frontera Norte.

Bobes, V. y PARdo, A. (2016), Política migratoria en México. Legislación, imaginarios $\quad$ y actores. FLACSO.

Dirección General de Atención a Migrantes, Veracruz (2017). Recuperado de https://bit.ly/3qt01yQ.

Filomeno, F. A. (2017). Theories of Local Migration Policy. Cham, Springer.

Fitzgerald, D. (2014). A Nation of Emigrants: How Mexico Manages its Migration. University of California Press.

Garrido de la Calleja, C. A. y Zavaleta Betancourt, J. A. (2020). Transformaciones y manipulaciones conceptuales de la migración en México. Apuntes para analizar su impacto político, legislativo y social. En MONTALVO Romero, M. T. (rec.) y FernándeZ AbAd, C. (coord.), Transformaciones de los conceptos claves en distintas áreas del conocimientos jurídico-social (pp. 241-264). Dykinson.

Garrido DE la CAllejA, C. A. (2017). Propuesta legislativa para la atención de migrantes en los gobiernos locales de México. El caso de Veracruz. En SÁNCHEZ Gavi, J. L., López Arévalo, J. y Vargas Vencis, P. (coords.), Acciones locales en materia migratoria (pp. 261-284). Universidad Autónoma de Chiapas, Benemérita Universidad Autónoma de Puebla, Universidad de Minnesota.

Gulasekaram, P. Y Karthick, R. (2015). The New Immigration Federalism. Cambridge University Press.

ImAZ, C. (2011). Marco de las políticas públicas sobre migración en México. En Chiarrello, L. M. (coord.), Las políticas públicas sobre migraciones y la sociedad civil en América Latina (pp. 483-522). Scalabrini International Migration Network.

INEGI (2020). México en cifras. Veracruz, Ignacio de la Llave. Recuperado de https: / / bit.ly/3JitFPI.

LA JORNADA (2021). Trump se autoelogia el muro y agradece a AMLO apoyo para frenar migración. Recuperado de https: / / bit.ly/3ennSKG.

LA JORNADA VERACRUZ (2014, 8 de mayo). Veracruz: el estado más violento contra migrantes. Albergue la 72.

Leigh, B. (2013). Tomorrow We're All Going to the Harvest. Temporary Foreing Worker Programs and Neoliberal Political Economy. University of Texas Press. 
LÓPEZ, A. (2019). La política migratoria mexicana en el primer semestre de la 4T en el marco del Pacto Mundial. En Reporte 11 sobre Migración en Puebla Migraciones en México, panorama y tendencias (pp. 44-67). Enero-Junio. Observatorio Ciudadano sobre Políticas Públicas para Migrantes-Puebla.

Ortega, A. (2013). Federalismo migratorio en México. Las oficinas estatales de atención a migrantes en un modelo comparativo nacional, Migraciones Internacionales, 7(1), 101-130.

Ortega, A. y Garrido de la Calleja, C. A. (2019). Políticas públicas de gobiernos estatales en materia migratoria, estudio comparativo de Puebla y Veracruz. En Giourguli, Lindstrom y Nájera, (coords.), Migraciones en las Américas. El Colegio de México.

PéreZ, M. E. (2007). Políticas migratorias en el Estado de Veracruz. En FernándeZ dE Castro, R., García Zamora, R., Clariond Rangel, R. y Vila Freyer, A. (coords.), Las políticas migratorias de los estados de México. Una evaluación (pp. 245272). ITAM, UAZ, Porrúa.

PNUD (2018). Conferencia Mundial Intergubernamental para la adopción del Pacto Mundial para una Migración Segura, Ordenada y Regular. Recuperado de https://bit.ly/3FxBT4r. PVD (2011). Plan Veracruzano de Desarrollo. Recuperado de https://bit.ly/32yZ4wv. SEGOB (2019). Entrega de tarjetas por razones humanitarias. Recuperado de https://bit.ly/3z0goGQ. 